Article

\title{
Numerical Analysis of End-Gas Autoignition and Pressure Oscillation in a Downsized SI Engine Using Large Eddy Simulation
}

\author{
Lijia Zhong and Changwen Liu * \\ State Key Laboratory of Engines, Tianjin University, Tianjin 300072, China; zhonglijia@tju.edu.cn \\ * Correspondence: liuchangwen@tju.edu.cn
}

Received: 30 August 2019; Accepted: 29 September 2019; Published: 15 October 2019

check for updates

\begin{abstract}
Knock and super-knock are abnormal combustion phenomena in engines, however, they are hard to study comprehensively through optical experimental methods due to their inherent destructive nature. In present work, the methodology of large eddy simulation (LES) coupled with G equations and a detailed mechanism of primary reference fuel (PRF) combustion is utilized to address the mechanisms of knock and super-knock phenomena in a downsized spark ignition gasoline engine. The knock and super-knock with pressure oscillation are qualitatively duplicated through present numerical models. As a result, the combustion and onset of autoignition is more likely to occur at top dead center (TDC), which causes end gas at a higher temperature and pressure. It is reasonable to conclude that the intensity of knock is not only proportional to the mass fraction of mixtures burned by the autoignition flame but the thermodynamics of the unburned end-gas mixture, and the effect of thermodynamics is more important. It also turns out that two auto-ignitions occur in conventional knock conditions, while only one auto-ignition takes place in super-knock conditions. However, the single autoignition couples with the pressure wave and they reinforce each other, which eventually evolves into detonation combustion. This work gives the valuable insights into knock phenomena in spark ignition gasoline engines.
\end{abstract}

Keywords: knock; super-knock; large eddy simulation (LES); end-gas autoignition; detonation

\section{Introduction}

Due to their advantages of high thermal efficiency and low emissions, turbocharging and downsizing engines represent the recent technical trend in downsized spark-ignited (SI) engines, as energy crisis and environmental pollution have become increasingly serious [1,2]. However, the inherent abnormal combustion phenomenon in SI engines, knock, represents the major obstacle for present SI engines to achieve ideal thermal efficiency [3]. Specifically, heavy knocking damages engines and produces noise that distracts drivers' attention. It is widely agreed that knock is caused by end gas auto-ignition before it is reached by the main flame initiated by the spark plug [4]. Furthermore, a new knocking mode called super-knock which produces huge destructive effects on engines has become a greater challenge for improving engine performance [5-10].

Many studies have been conducted to investigate the mechanisms of knock and super-knock [11-23]. Konig et al. [11] observed the flame propagation and auto-ignition events by using high-speed natural light and Schlieren photography. Their results showed a multiple centering and stochastic nature of auto-ignition, and the severity of knock increased as the onset of auto-ignition occurred closer behind the top dead center (TDC). Merola et al. [24] carried out a series of experiments in a four-stroke SI engine with optical techniques based on natural flame emission imaging and ultraviolet spectroscopy to investigate the relationship between intermediate products and the start time, duration of knock 
and auto-ignition (AI) kernel. Their research revealed that HCO radicals arei strongly correlated with the occurrence of auto-ignition while the burned region with high temperature can be modeled by $\mathrm{OH}$ radicals. Based on this work, Kawahara et al. [25] took a step forward and pointed out that $\mathrm{OH}$ radicals can be adopted to identify the transition from low-temperature reactions to high-temperature reactions. Besides, researchers have explored a majority of the characteristics that may influence knock, including the initial temperature and properties of fuel [26], octane tic sensitivity [27], and advanced techniques such as homogeneous charge compression ignition (HCCI) [28]. Wang et al. [29,30] captured the super-knock in a closed system by using a rapid compression machine and high-speed direct photography, and their results demonstrated that the mechanism of super-knock consists of a heat-induced deflagration to detonation. Furthermore, they pointed out that the detonation was firstly initiated near the wall. Those experiments play an important role in understanding the knock phenomenon, however, with experimental methods is hard to comprehensively recognize knock or super-knock combustion due to their extremely destructive features and the complicated nature of knock which combines turbulent flow, flame propagation, end-gas auto-ignition, pressure oscillation, turbulent-combustion interactions and pressure wave-chemical reactions interactions.

Thanks to the blooming development of high-performance computing clusters, the CFD method has been proved able to help us understand abnormal combustion mechanisms [31-35]. In the 1-D numerical field, Livengood and $\mathrm{Wu}$ [36] proposed an equation to predict the occurrence of auto-ignition in unburned mixtures. Based on this work, Heywood et al. [37] introduced the influence of burned mixtures on end-gas unburned mixtures, and they divided the combustion chamber into burned region and unburned region, proposing that the compression and heating effect from burned mixtures is prone to promote the end-gas auto-ignition. The two studies focused on the end-gas AI, but they could not predict the pressure oscillation and flame propagation after the occurrence of AI, let alone consider the influence of turbulence and the structure of the combustion chamber. In 3-D simulations, the Reynolds averaged Navier-Stokes (RANS) approach provides today precise predictions of mean quantities such as temperature or pressure in internal combustion engines. Notably, RANS simulations were conducted to predict and understand the occurrence of knock [38,39] and super-knock [40]. However, as the definition suggests, the RANS method is limited because it focuses on describing the mean cycle, which is not suitable for knock or super-knock due to their transient characteristics. On the other hand, direct numerical simulations (DNS) for 3-D investigations still remain costly.

The recent development of LES tools has opened new perspectives in the combustion field without losing computational efficiency. Some works of Robert et al. [41] showed that LES could capture knock characteristics such as intensity and frequency over a wide range of ST. Pinaki et al. [42] proposed a LES model coupled with G equation and skeletal mechanism of a primary reference fuel (PRF) to predict knocking combustion in a cooperative fuel research engine. The model was able to predict the no knock to knock transition precisely as the compression ratio was increased. Especially, it made great agreements in the critical compression ratio at knock onset with experimental data for two different PRF blends. However, only slight knock phenomena could be observed. Lecocq et al. [43] proposed a new LES model coupled with the flame surface density and Tabulated Kinetics for Ignition (TKI) approaches to investigate knock and pre-ignition in downsized gasoline engines, whereas Robert et al. [32] pointed out that both the Extended Coherent Flame Model for LES (ECFM-LES) and TKI methods were not able to fully decouple the premixed flame and auto-ignition phenomena. Therefore they improved the ECFM-LES method and applied it successfully to simulating a multi-cycle SI engine under general knock and super-knock conditions. Their results show that knock intensity is positively proportional to the fresh gases mass burned by auto-ignition at low knock intensities, while for super-knock, the knock intensity is also proportional to the fresh gases consumed by auto-ignition but with a much higher factor. Moreover, the deflagration to detonation transition (DDT) is observed in super-knock, where a coupling between pressure wave and the AI reaction rate appears, leading to maximum pressures and propagation speeds close to those of detonation. However, the in-depth mechanism of the combustion 
mode transition from normal combustion to super-knock combustion is not clear yet, the relevant work is still limited and the further work needs to be done.

Therefore, the main objective of the present work is to numerically investigate the in-depth mechanism of different combustion modes in a practical spark ignition engine. The knock and super-knock phenomena are achieved by changing the spark timing, and the in-depth mechanisms responsible for the combustion mode transition from normal combustion to super-knock combustion are carefully addressed in terms of the evolutions of the pressure wave, $\mathrm{HCO}$, flame surface and unburned temperature distributions. A spark timing variation in the experimental database is well simulated in LES, in which the methodology of LES coupled with G-equations and detailed chemistry mechanism of primary reference fuel are carried out. Importantly, the present model performance is validated and evaluated even when super-knock occurs. Thus, the turbulent flame propagation is determined by the G-equations turbulent combustion model, meanwhile the detailed chemistry mechanism based on SAGE solver is employed to capture the end-gas autoignition process. This work will give the valuable insights for the spark ignition gasoline engine to further improve the performance.

The remaining of the paper has the following structure: the experimental apparatus and procedure are presented in Section 2. In Section 3, the numerical settings including LES equations, combustion model, and other numerical models are comprehensively demonstrated. The validation of the present model and the general combustion phenomena are also provided here. Subsequently, the knock and super-knock combustion mechanism obtained through simulation are discussed in Section 4. Finally, a conclusion that summarizes our main findings is presented.

\section{Experimental Setting}

\subsection{Experimental Apparatus}

Experiments are conducted in a single-cylinder, four-stroke Ricardo E6 engine equipped with a direct-current dynamometer. The engine combustion chamber contains of an approximately plane piston and a pent-roof cylinder head. A Siemens VDO piezoelectric injector for a BMW vehicle is used for injection. Variable valve timing and lift is achieved by a hydraulically powered Variable Valve Actuation system. A wideband lambda sensor is used to measure equivalence ratio which has a resolution of 0.001 and uncertainty of $\pm 0.8 \%$. A Kistler $6118 \mathrm{~B}$ pressure transducer and a Kistler 5018 charge amplifier are used to capture and amplify the in-cylinder pressure signals. The natural frequency is approximately $90 \mathrm{kHz}$. Pressure signals are measured by a combustion analyzer with resolution of $0.1{ }^{\circ} \mathrm{CA}$. A fuel consumption meter ranging from $0 \mathrm{~kg} / \mathrm{h}$ to $5 \mathrm{~kg} / \mathrm{h}$ with accuracy of $\pm 0.2 \%$ is placed to measure fuel mass. The temperatures of lubricating oil and coolant are controlled by a SIEMENS PID controller with uncertainty of $\pm 3{ }^{\circ} \mathrm{CA}$. A Toceil LFE060 flow meter is chosen for measuring the inlet mass flow rate with uncertainty of $\pm 1 \%$.

\subsection{Experimental Procedure}

A full load with engine speed of $1600 \mathrm{rpm}$ is chosen to investigate knock in direct injection spark ignition (DISI) engines. The detailed operating conditions are shown in Table 1. The engine is firstly operated under general combustion conditions, and then its spark timing is advanced gradually until obvious pressure oscillation and a knocking sound can be observed. Results show that knock does not take place when the spark timing is 8, 10,12 CAD bTDC while a slight knock can be observed when the spark timing is $14 \mathrm{CAD}$ bTDC. With the further advance in spark timing, the knock grows stronger. At the condition of 18 CAD bTDC, the knock becomes strongly destructive as the knocking sound becomes grating. Figure 1 demonstrates the evolution of cylinder pressure and pressure oscillation filtered by a high-pass FFT filter. The high-pass filter with a cutoff $4 \mathrm{kHz}$ is used to distinguishing the pressure oscillations from the original in-cylinder pressure signals. Here, the pressure value in general combustion condition is the average cylinder pressure of 200 consecutive cycles. For knock condition, the cylinder pressure is obtained at the max maximum amplitude of pressure oscillations (MAPO) 
cycle [44]. Along with the advance in spark timing, the maximum pressure increases gradually, until knock occurs. Further advance in spark timing will strengthen knock and increase the amplitude of pressure oscillation. When sparking advance timing is $18 \mathrm{CAD}$ bTDC, the amplitude of pressure oscillation exceeds $0.5 \mathrm{MPa}$, which indicates a strong knock. And further advancing the spark timing will destroy the engine, thus the very strong knock or super-knock can't be observed in this experiment.

Table 1. Operating conditions.

\begin{tabular}{cc}
\hline Parameter & Value \\
\hline Compression ratio & $10: 1$ \\
Rotational speed & $1600 \mathrm{rpm}$ \\
Throttle angle & Fully open \\
Equivalence ratio & 1.0 \\
Intake pressure & $1 \mathrm{~atm}$ \\
Intake temperature & $25^{\circ} \mathrm{C}$ \\
Injection pressure & $125 \mathrm{bar}$ \\
Injection timing & $240 \mathrm{CAD} \mathrm{bTDC}$ \\
Fuel & $\mathrm{RON} 92(\mathrm{PRF} 92)$ \\
Fuel consumption & $1.64 \mathrm{~kg} / \mathrm{h}$ \\
Spark timing & $-8,-10,-12,-14,-16,-18 \mathrm{CAD}$ \\
IVO/IVC & $350 / 590 \mathrm{CAD}$ \\
EVO/EVC & $160 / 380 \mathrm{CAD}$ \\
\hline
\end{tabular}

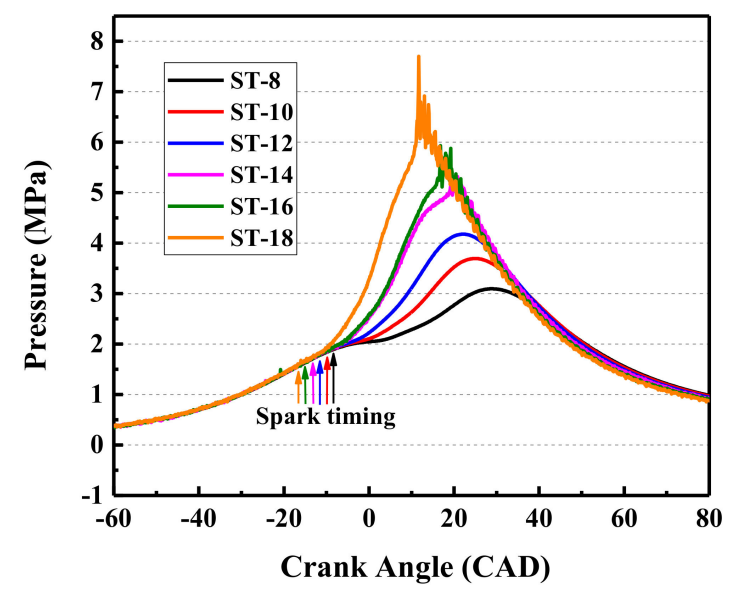

(a)

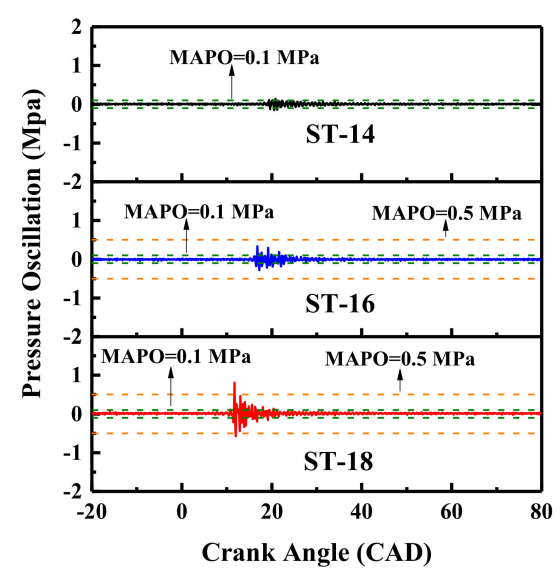

(b)

Figure 1. Pressure traces (a) and filtered pressure oscillations (b) with different spark timings. 


\section{Numerical Settings}

\subsection{Turbulent Combustion Model}

In a spray-guided GDI engine, partially pre-mixed combustion may occur [45]. The G-equation-based turbulent combustion model [46] is usually applied for partially pre-mixed combustion with chemical kinetics. Based on the above considerations, a skeletal chemical kinetics mechanism of a primary reference fuel (PRF) with 48 species and 152 elementary reactions for isooctane and $n$-heptane [47] is used in this work. The G-equation-based turbulent combustion model is used supposing to calculate the average flame surface. Detailed transient chemistry solver (SAGE) [48] is applied to mimic fuel consumption after flame front and auto-ignition prior to flame front. The flame front is defined as the boundary where $G$ is -0.001 . The average flame surface where $G$ is 0 divides the combustion chamber into unburnt region $(G<0)$ and burnt region after the average flame surface $(G>0)$. The $G$-equation is [49]:

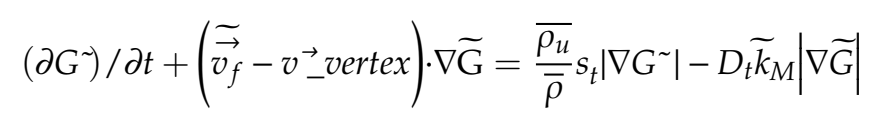

Here $\widetilde{G}$ is Favre-averaged G. $\widetilde{\overrightarrow{v_{f}}}$ is the Favre mean bulk fluid velocity in the flame front. $\vec{v}_{\text {vertex }}$ is the mesh vertex velocity. $\overline{\rho_{u}}$ is unburned mixture density. $\bar{\rho}$ is the mean gas density of turbulent flame. $D_{t}$ is turbulent diffusivity. $\widetilde{k}_{M}$ is mean flame curvature. $s_{t}$ represents turbulent flame speed.

$s_{t}$ is the function of laminar flame speed $\left(s_{l}\right)$ and Damköhler number. It is expressed as follows [49]:

$$
s_{t}=s_{l}+v^{\prime}\left\{-\frac{a_{4} b_{3}^{2}}{2 b_{1}} D a+\left[\left(\frac{a_{4} b_{3}^{2}}{2 b_{1}} D a\right)^{2}+a_{4} b_{3}^{2} D a\right]^{\frac{1}{2}}\right\}
$$

where $v^{\prime}$ is turbulence intensity. Other parameters such as $a_{4}, b_{1}$ and $b_{3}$ are constants derived from turbulence model. $D a$ is the Damköhler number, which establishes the relationship between chemical kinetic and flame development.

To mimic the laminar flame speed, Metghalchi and Kech correlation [50] is adopted in this study:

$$
s_{l}=s_{l-r e f}\left(\frac{T_{u}}{T_{u, r e f}}\right)^{\alpha}\left(\frac{P}{P_{r e f}}\right)^{\beta}\left(1-2.1 Y_{d i l}\right)
$$

$T_{u}$ is the unburnt mixture temperature, $T_{u, r e f}$ equals to $298.0 \mathrm{~K} . P$ is the unburnt mixture pressure, $P_{\text {ref }}$ is 1.01 bar. $Y_{\text {dil }}$ is the mass fraction of the dilution species. $\alpha$ and $\beta$ are the exponent for temperature and pressure:

$$
\begin{gathered}
\alpha=2.18-0.8(\phi-1) \\
\beta=-0.16-0.22(\phi-1)
\end{gathered}
$$

$s_{l-r e f}$ is obtained by the Gülder correlations [51]:

$$
s_{l \_r e f}=\omega \phi^{\eta} \exp \left[-\xi(\phi-\sigma)^{2}\right]
$$

Here, $\omega, \eta, \xi$ and $\sigma$ are modeling constant coefficients for isooctane/air mixture.

\subsection{Numerical Models}

The 3D methodology of LES coupled with G-equation and a chemical kinetic model for primary reference fuel (PRF) oxidation in CONVERGE CFD code is applied for the simulation performed in this study. Here, the large eddy simulation coupled with one equation viscosity model $[52,53]$ is adapted to simulate the turbulence. The KH-RT breakup length model [54] that includes Kelvin-Helmholtz instability and Rayleigh-Taylor instability mechanisms is utilized to predict the breakup of fuel droplets. 
The wall heat transfer process is modeled by the O'Rourke and Amsden model [55]. The geometry model which consists of a combustion chamber, an inlet port and an outlet port together with its grid splitting can be found from Figure 2. The simulation starts at -440 CAD aTDC, with a duration of the whole working cycle. The base grid size is $1 \mathrm{~mm}$, with a fix embedding around spark plug and spray to meet mesh resolution requirement. Furthermore, adaptive mesh refinement (AMR) is adopted in spray and reaction region. During combustion, the average cell size in flame front is of the order of $0.5 \mathrm{~mm}$. The number in spray and spark plug region during injection process and ignition process is $0.25 \mathrm{~mm}$ and $0.125 \mathrm{~mm}$, respectively. A maximum cell number of 4 million is achieved. Note that the present grid resolution is able to predict the super-knock occurrence according previous work [32]. The time step adjusts itself according to the CFL number and convection speed, varying from $1 \times 10^{-8} \mathrm{~s}$ to $1 \times 10^{-6} \mathrm{~s}$. The simulations are performed at Tianhe Super-computer Platform and the computational cost of the knock case is on the order of 5 days. Twelve monitor points are allocated evenly around the combustion chamber to capture pressure oscillation. Owing to the stochastic nature of knock, the cycle-to-cycle variation in knock condition exists, so the mean cylinder pressure and mean heat release rate of 200 cycles in general combustion condition are chosen to validate the model. In this work, we only focus on the knock mechanism, thus, the effect of cycle-to-cycle variations is neglected.

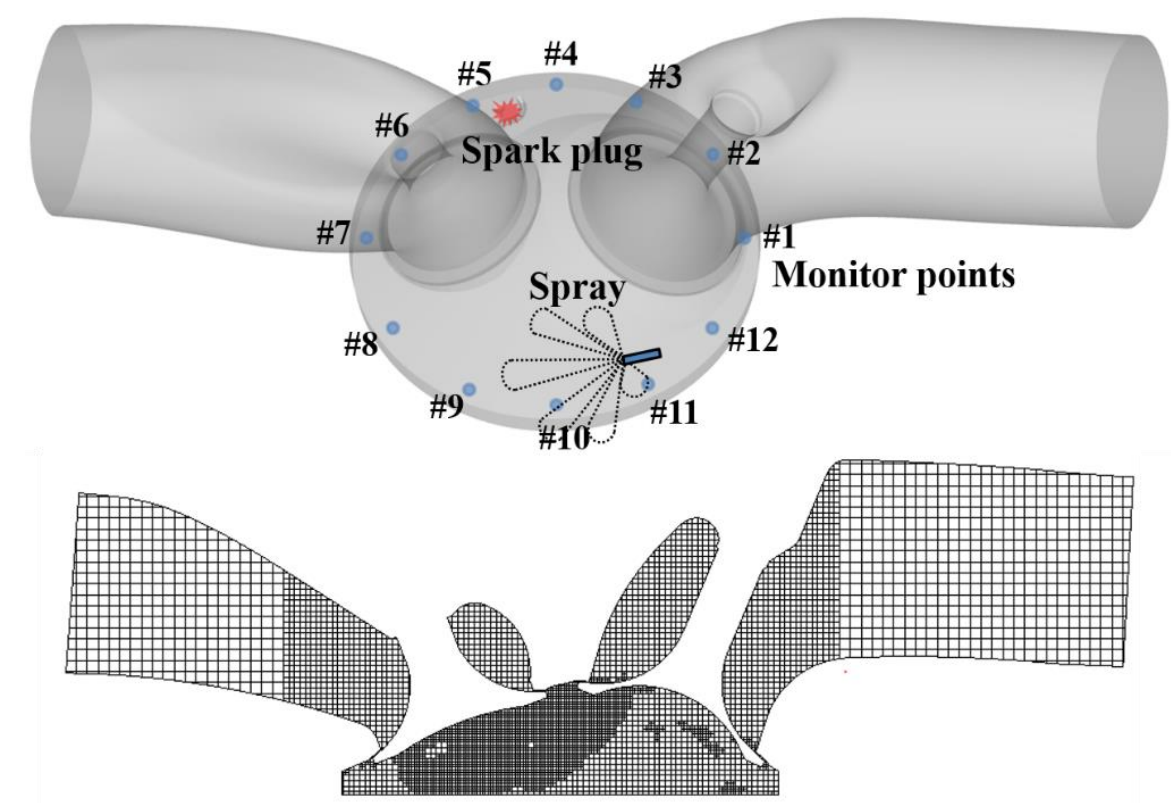

Figure 2. Schematic of the model structure and grid splitting.

\subsection{Model Validations}

Figure 3 describes the numerical and experimental results of cylinder pressure and Heat Release Rate (HRR) at $-10 \mathrm{CAD}$ as a reference. It should be seen that combustion progress at spark timings vary from -8 to -12 show similar results. As can be seen, the predicted pressure profile agrees with the experimental results well. In this spark timing, knocking combustion is neither identified by experiment nor by LES. Advancing the spark timing to -18 CAD TDC is used to further validate the model in knock conditions as shown in Figure 4. The numerical result denoted by red lines is seen to be correctly distributed from the bottom to the top of the experiment envelop, and the amplitude of pressure oscillation is similar to experimental results, too. LES very well captures the knocking combustion phenomenon. Those results provide favorable evidence that the present model is able to simulate knock in engines.

Limited by the structure strength of engine, the maximum spark advance angle is -18 CAD in experiment, the $\mathrm{MAPO}$, however, is below $1 \mathrm{MPa}$, which corresponds to conventional knock as a reference. While in simulations, the spark advance angle can be further increased to investigate strong 
knock or even super-knock by LES method. In present work, the knock progress at the spark timing of $-20,-22,-24,-26,-28$ CAD is investigated. These conditions are defined as ST-20, ST-22, ST-24, ST-26 and ST-28, while the elementary case is ST- 18 .

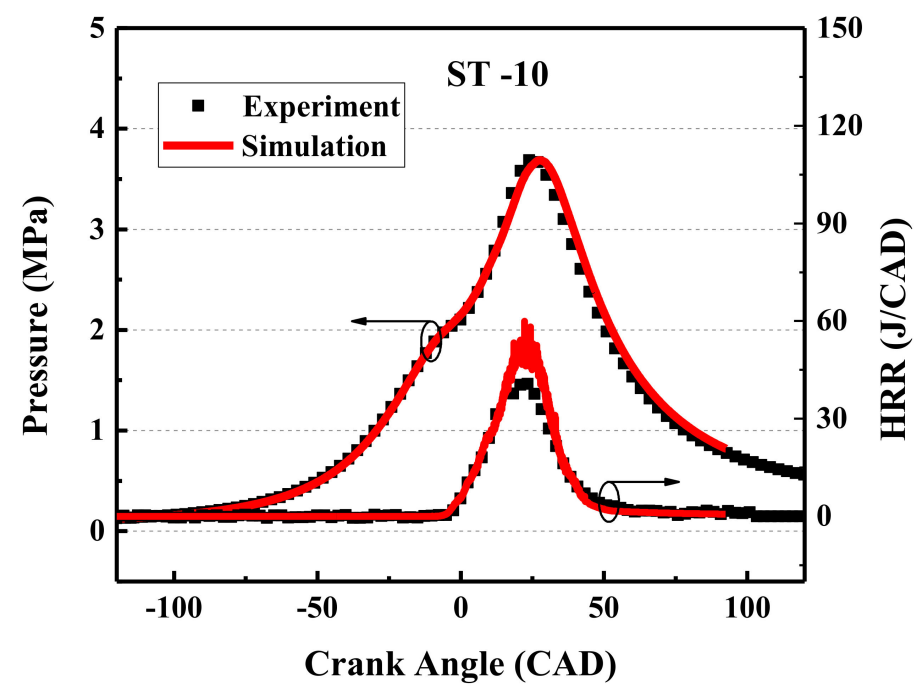

Figure 3. The numerical and experimental results of cylinder pressure and HRR at different spark timings.

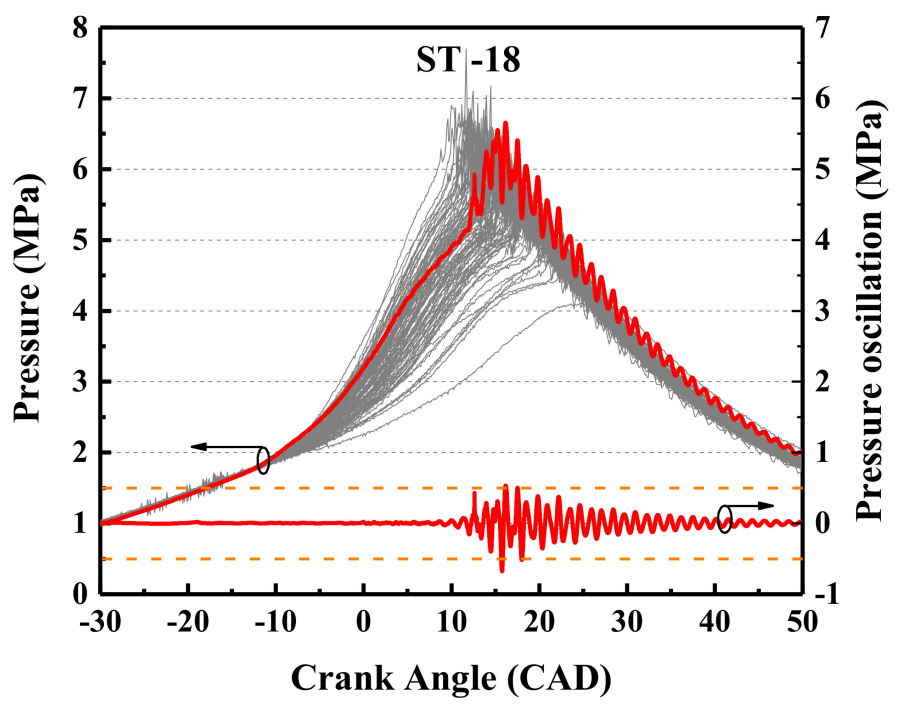

Figure 4. Comparison of numerical and experimental results on pressure trace and filtered pressure oscillations under knock condition.

\subsection{General Combustion Phenomena Using LES}

The evolution of pressure and filtered pressure oscillation is demonstrated in Figure 5. Figure 6 shows the MAPO and onset of auto-ignition which is obtained from the 3-D simulation results under different spark timings. From ST-18 to ST-24, the knock grows stronger with earlier onset and higher amplitude as spark timing advances, the MAPO, however, is still lower than $5 \mathrm{MPa}$, which indicates the low intensity of knock. At ST-26 and ST-28, the peak pressure and amplitude of pressure oscillation increase steeply, reaching a value of $30 \mathrm{MPa}$ and $25 \mathrm{MPa}$, respectively. Obviously, super-knock occurs in these cases. 


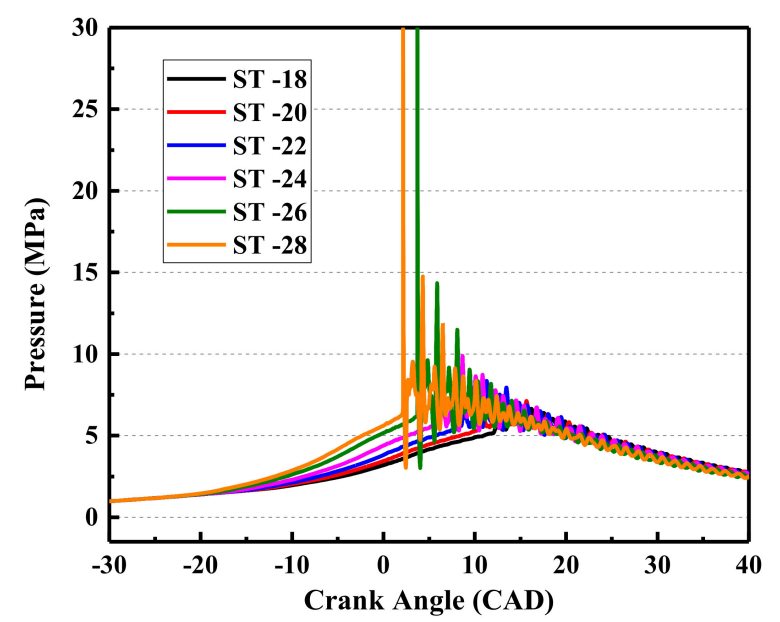

(a)

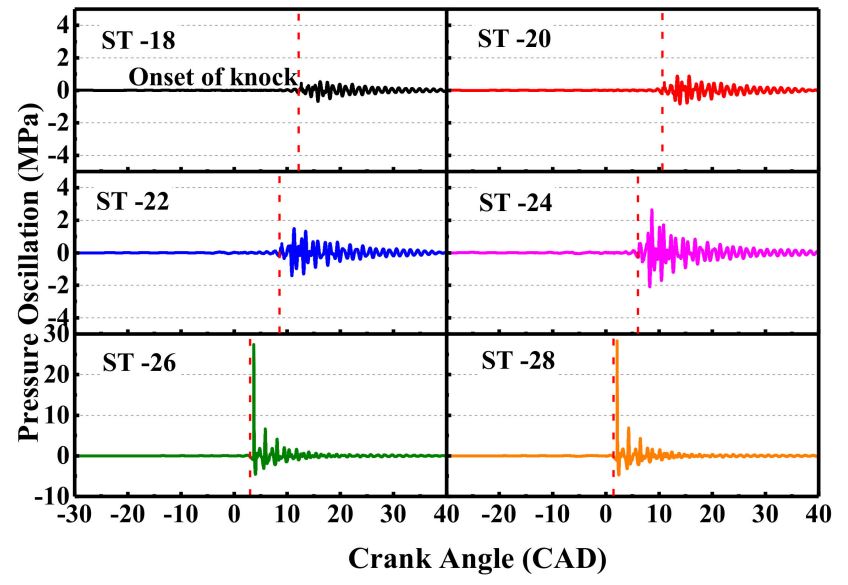

(b)

Figure 5. Pressure trace (a) and filtered pressure oscillations (b) at different spark timings.

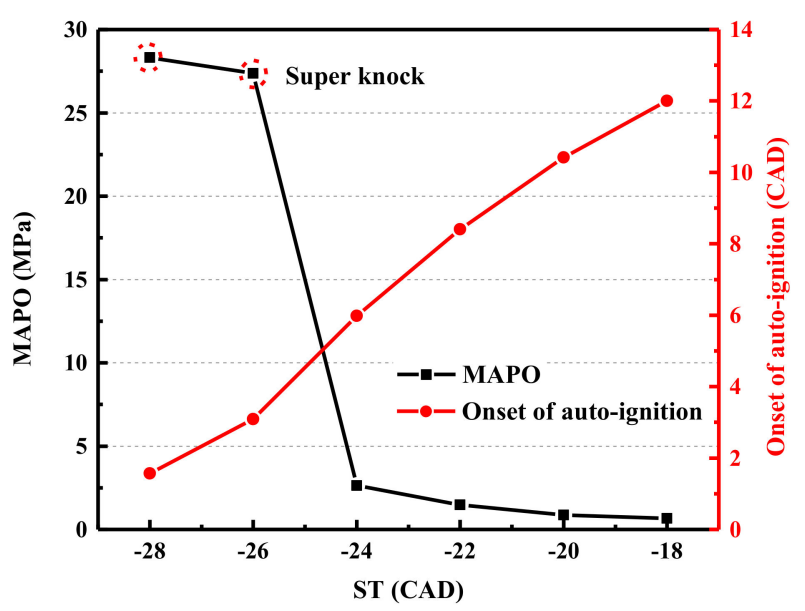

Figure 6. MAPO and onset of auto-ignition at different spark timings.

Figure 7 demonstrates the evolution of HRR and burned mass fraction (BMF) under different spark timings. The curves of HRR exhibit a bimodal shape between ST-18 and ST-24. Besides, the advance in spark timing will advance the appearance of peak pressure and increase its value while shorten the duration of heat release. The bimodal shape of HRR indicates that the end gas is not completely consumed by the first auto-ignition. The first auto-ignition decays into a deflagration, after 
which a new auto-ignition occurs between the main flame and deflagration, causing the second rising in heat release rate. At -26 CAD and -28 CAD, an obviously unimodal shape of HRR is observed, with a much higher peak value. The BFM increases steeply, and $25 \%$ of mixture is consumed during 1 CAD. These results reveal that the auto-ignition occurs sequentially in an extremely short time. Similar results can be concluded in 3D results. Though distinct differences can be found in cylinder pressure and HRR between conventional knock and super-knock, the BMF denoted by pentagrams in Figure 7 is similar under different spark timings when auto-ignition occurs. Thus, it can be drawn that the knock intensity does not depend on the mass fraction of unburned mixture when AI takes place, but its thermodynamic conditions. The onset of AI gets closer to TDC as spark timing advances, which will bring out higher cylinder pressure and temperature. As a result, the heat release of end-gas is more violent at the auto-ignition process, producing higher local pressure increase, which externalizes a stronger knock. As pointed out in [41], the knock intensity is related to the fuel mass percentage consumed by AI and pressure wave intensity is proportional to the fuel mas burned by AI, however, in this process the thermodynamics conditions as well as pressure wave also play important roles observed in this work. To further investigate the combustion mechanisms of conventional knock and super-knock in cylinder, ST-18, ST-22, ST-26 and ST-28 are analyzed.

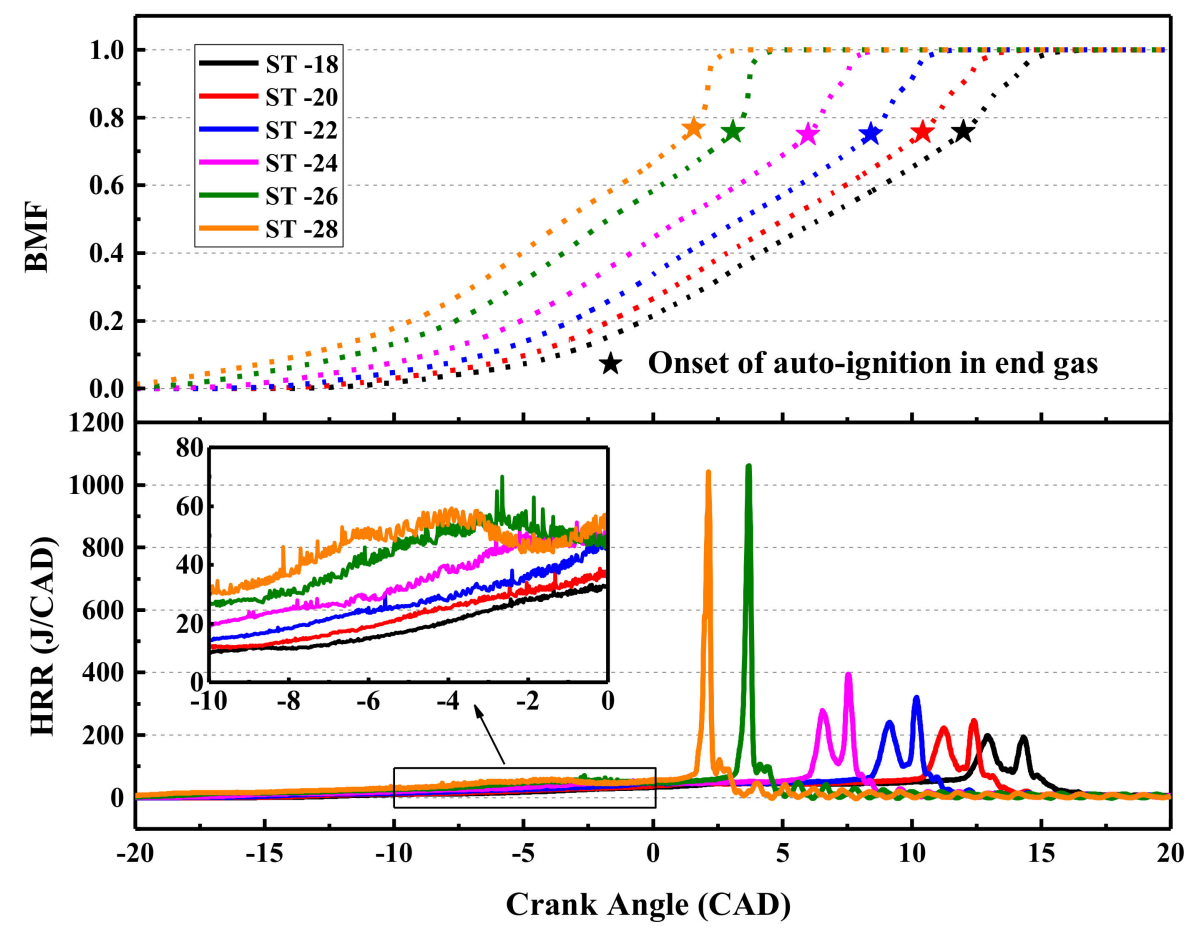

Figure 7. HRR and BMF curves at different spark timings.

\section{Results and Discussion}

\subsection{Knock Combustion Mechanism}

In ST-18, ST-20, ST-22 and ST-24, the knock intensity increases as spark timing advances, however, all of them belong to knock due to their relatively low cylinder pressure and HRR. Thus, ST-18 and ST-22 are chosen as the example case to analyze the in-cylinder combustion process of conventional knocks with different intensity.

\subsubsection{Combustion Progress in ST-18}

Figure 8 shows the 3D evolution of in-cylinder combustion process of ST-18. Here, the isosurface for $G=0$ denoted by the red surface represents the flame front induced by spark ignition [49]. The onset of auto-ignition is localized by an isosurface of $\mathrm{HCO}$ with a mass fraction of $3.0 \mathrm{ppm}$ [24] and the 
isosurface where the unburned temperature is $1600 \mathrm{~K}$ represents the flame front induced by auto-ignition. Reference [24] experimentally revealed that the HCO radical is strongly correlated to the occurrence of auto-ignition while the high temperature burned region can be modeled by $\mathrm{OH}$. The distribution pattern of pressure fluctuation $(\Delta \mathrm{P})$ in the horizontal cross-section which is the value of the differential between the local pressure and the average pressure in cylinder is demonstrated. Three distinct different combustion stages, including main flame propagation, first auto-ignition propagation and second auto-ignition can be found. The deflagration ignited by spark spreads outwardly from the spark plug, with a relatively low heat release as a result of the low flame propagation velocity. The local pressure increase caused by the combustion at the flame front is balanced immediately, thus, no local pressure differential is caused in the first stage. The temperature and pressure of end gas rise continuously under the compression and preheating of burned gas induced by the main flame propagation. Owing to the inhomogeneity in temperature and species distribution, an auto-ignition occurs at hot spot. In ST-18, the auto-ignition occurs near the cylinder wall at 12.1 CAD, with lots of $\mathrm{HCO}$ radicals produced by low temperature reactions being accumulated. As the temperature increases, $\mathrm{HCO}$ radicals are consumed quickly, forming a stable flame front spread outwardly. The AI induces much higher HRR compared to main flame, causing a steeply increase in local pressure, which ultimately result in the generation of pressure wave. Note that in the present discussion, the AI 1 and AI 2 do not represent the only two autoignition points, but similar auto-ignition points in temporal and spatial evolution approximately are regarded as one auto-ignition point. For example, in the first auto-ignition, a new auto-ignition kernel appears at 12.4 CAD. However, the new AI kernel is so close to the initial auto-ignition flame front that they couple with each other immediately, forming a new flame front (see 12.7 CAD and 13 CAD). Sequential auto-ignitions do not appear around the first auto-ignition owing to the insufficient thermodynamic state, instead, it turns into a deflagration flame. The newly generated flame as well as the main flame compresses the unburned mixture, leading to a huge increase in local temperature and pressure, which triggers the second auto-ignition. The second auto-ignition has a higher intensity compared to the first one owing to the fact that the second auto-ignition occurs in a mixture with higher temperature and pressure. Mixtures around it are consumed in a short time (from 14.1 CAD to 14.5 CAD), causing a sharp heat release, which generates strong pressure waves. Those pressure waves propagate back and forth, leading to the pressure oscillation.

Figure 9 demonstrates the distribution of pressure fluctuation, mass friction of $\mathrm{HCO}$ and unburned temperature in the horizontal cross-section under different time. The purple line represents the contour of $G=0$, which is utilized to locate the main flame. Similar to it, the auto-ignition flame front is localized by an isoline (black line) of HCO with a mass fraction of $3.0 \mathrm{ppm}$. High HCO concentration region indicates the strong intensity of low temperature reaction of autoignition. It can be seen that, after the initial autoignition kernel formation, $\mathrm{HCO}$ is mainly generated in a very thin area near the auto-ignition flame front, which can be used to identify the location of auto-ignition flame front. As can be clearly seen from the diagram, two auto-ignitions take place one by one at 12.1 CAD and 14.1 CAD, respectively. The first auto-ignition occurs near the cylinder wall, while the second auto-ignition occurs ahead of the flame front. This result confirms the stochastic nature of auto-ignition, which is consistent with the optical results in experimental work. It is noted that in this condition, sequential auto-ignitions do not occur after the initial flame kernel is formed, so the pressure wave propagates away from the auto-ignition point. As a result, no coupling between flame front and pressure wave is formed. 


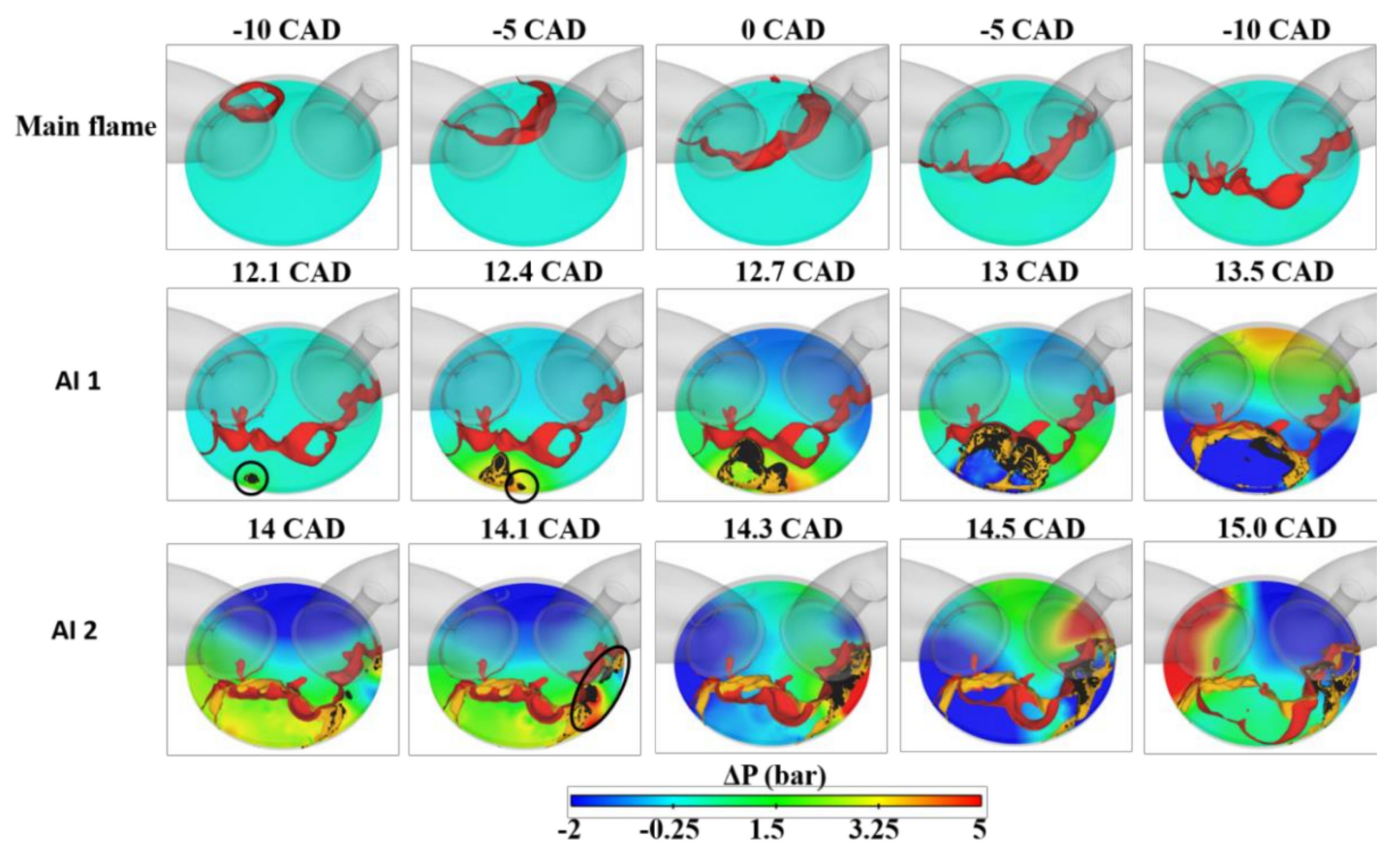

Figure 8. Evolutions of 3D in-cylinder combustion process including the propagation of spark-induced flame, auto-ignition in the end-gas and pressure oscillation triggered by auto-ignition.

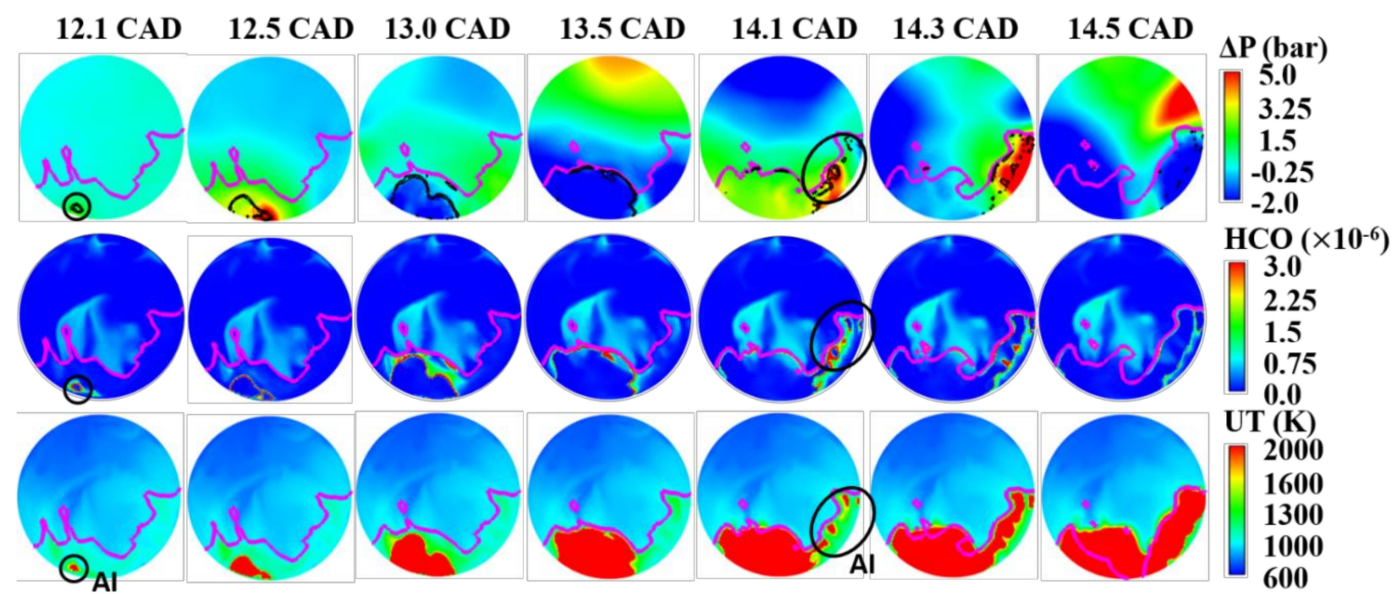

Figure 9. Evolutions of $\triangle \mathrm{P}$, mass fraction of $\mathrm{HCO}$ and unburned temperature after the initial auto-ignition at $\mathrm{ST}=-18 \mathrm{CAD}$.

\subsubsection{Combustion Progress at ST-22}

Figure 10 demonstrates the combustion progress at $\mathrm{ST}=-22 \mathrm{CAD}$. The result shows that at 8.5 CAD, the first auto-ignition takes place, slightly earlier than at $\mathrm{ST}=-18 \mathrm{CAD}$, the location where the auto-ignition occurs, however, remains the same. The flame induced by auto-ignition at ST-22 propagates faster than at ST-18 due to the higher thermodynamics of unburned mixture when auto-ignition occurs. Moreover, ST-22 has shorter interval between two auto-ignitions. The second auto-ignition takes place at $10 \mathrm{CAD}$ in the same position as ST-18 with faster propagating velocity, inducing stronger pressure oscillations. It can be seen from Figure 11 that the distribution area of HCO in unburned mixture for ST-22 is larger than that for ST-18, which means more unburned mixture are involved into auto-ignition, bringing a much more intense heat release. Two pressure waves generated by the first and the second auto-ignition respectively can be clearly observed from the distribution pattern of $\Delta \mathrm{P}$. These two pressure waves propagate perpendicularly without superposition or coupling, which can't cause the strong knock intensity. 


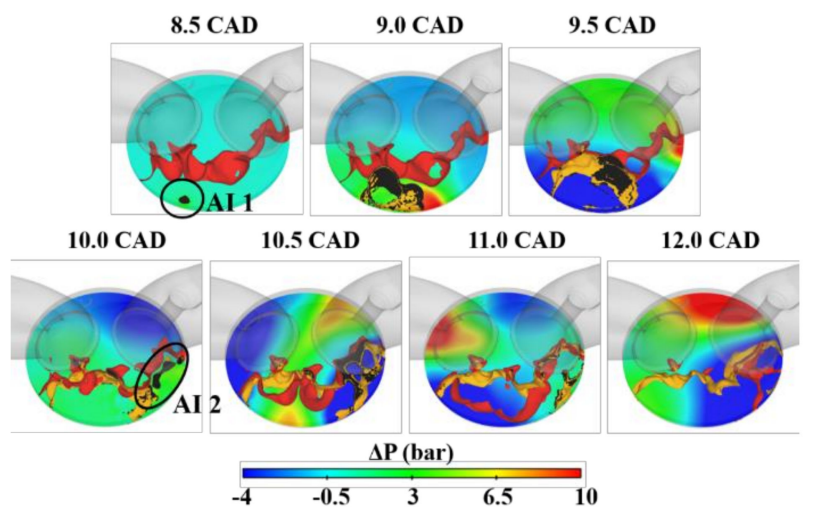

Figure 10. Evolutions of $3 \mathrm{D}$ isosurfaces of $\mathrm{G}=0$ and $\mathrm{T}=1600 \mathrm{~K}$ in-cylinder combustion process at $\mathrm{ST}=-22 \mathrm{CAD}$.

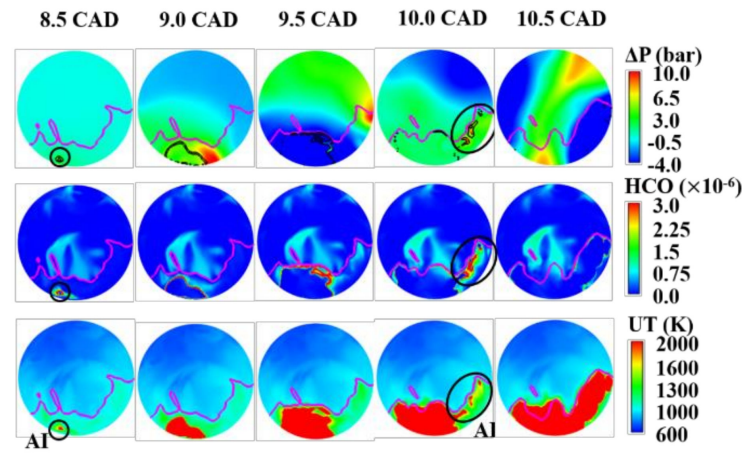

Figure 11. Evolutions of $\triangle \mathrm{P}$, mass fraction of $\mathrm{HCO}$ and unburned temperature after the initial auto-ignition at $\mathrm{ST}=-22 \mathrm{CAD}$.

To further investigate the coupling between flame and pressure wave, the pressure, temperature and mass fraction of $\mathrm{HCO}$ are extracted from a circular path which passes through the AI point. Details of the tracing method can be found in Figure 12. The two black curves shown in the figure are two concentric circles of $3 \mathrm{~mm}$ (curve 1) and $8 \mathrm{~mm}$ (curve 2) away from the cylinder wall, which pass through the two auto-ignition points as shown in Figure 12, respectively. Basically, the main flame propagates outwardly from the spark plug, and the unburned mixture is distributed between cylinder wall and main flame. Hence, it is reasonable to conclude that the direction of auto-ignition flame propagation is basically consistent with the direction of circular path.

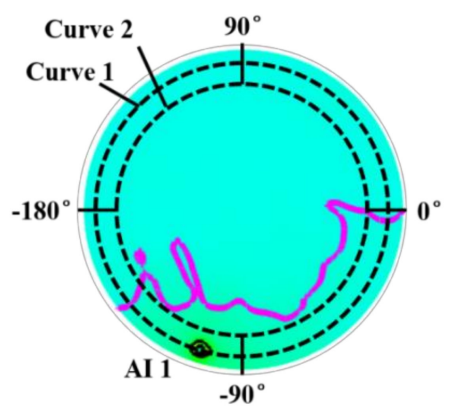

(a)

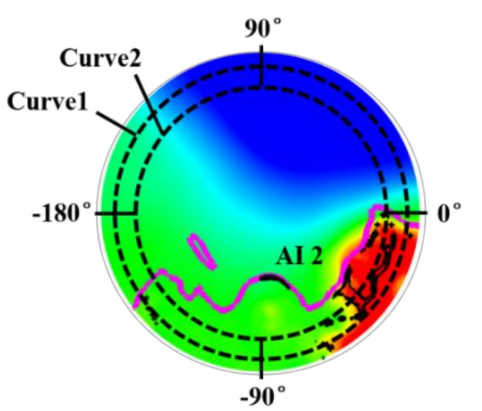

(b)

Figure 12. Schematic of the trace from which the 1D profile is extracted.

Figure 13 shows the evolution of $2 \mathrm{D}$ configuration of $\Delta \mathrm{P}$ in the horizontal cross-section (left), pressure, unburned temperature and mass fraction of HCO on the 1D profile (middle) and 2D configuration of unburned temperature in the horizontal cross-section (right) under the condition 
of ST-22. HCO as the cause of autoignition in the end gas is employed at the onset of knocking. The temperature and pressure of AI point increase immediately after the auto-ignition that occurs at $8.5 \mathrm{CAD}$, while at the same time, $\mathrm{HCO}$ production occurs by low temperature reactions near the auto-ignition flame front. The first auto-ignition core quickly evolves into a propagating flame, with a velocity lower than the velocity of pressure wave. The pressure wave is ahead of the flame. At 10 CAD, the second auto-ignition occurs between the main flame and the first AI flame. No flame propagation from the latter auto-ignition is observed because of multi-point autoignition and thermal explosion. As the most of unburned mixture is consumed by the flame induced by first auto-ignition, consequently the unburned mixture consumed by the occurrence of the second AI is small, which leads to a small pressure rise of about $1 \mathrm{MPa}$. Besides, it can be seen from the one-dimensional diagram that no coupling between flame front and pressure wave appears at any instant, thus the flame propagation is only normal auto-ignition and deflagration propagation. As a result, it is evident that the deflagration to detonation transition does not occur here.
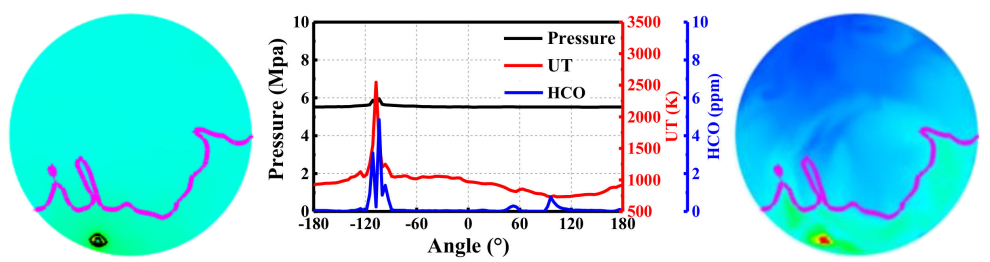

(a) $8.5 \mathrm{CAD}$
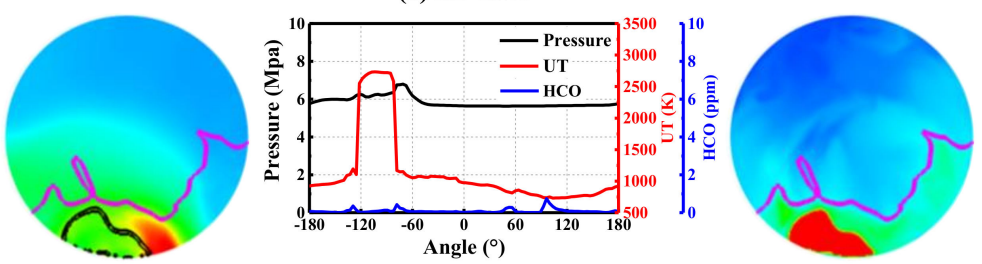

(b) 9.0 CAD
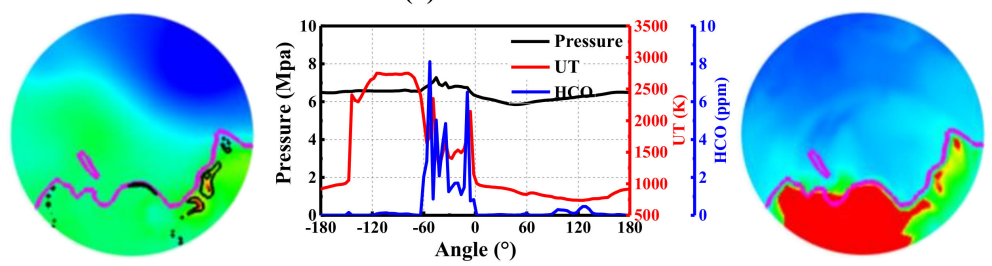

(c) 10.0 CAD
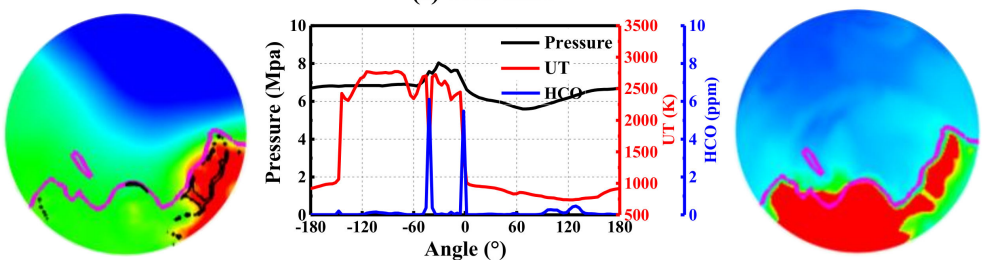

(d) 10.1 CAD
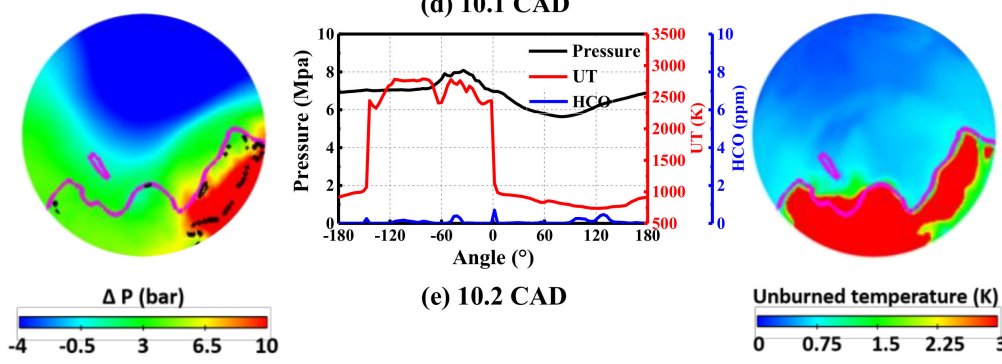

(e) 10.2 CAD

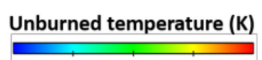

Figure 13. Evolutions of $2 \mathrm{D}$ configuration of $\Delta \mathrm{P}$ in the horizontal cross-section (left), pressure, unburned temperature and mass fraction of $\mathrm{HCO}$ on the 1D profile (middle) and 2D configuration of unburned temperature in the horizontal cross-section (right) under the condition of ST $=-22$ CAD. (a-e) corresponding to five different angles. 


\subsection{Super-Knock Combustion Mechanism}

Super-knock appears at ST-26 and ST-28, as their MAPOs exceed $25 \mathrm{MPa}$, which are far away from other spark timings. Therefore, ST-26 is taken as an example to analyze the combustion mechanism of super-knock. Figure 14 demonstrates the 3D evolution of in-cylinder combustion process at ST-26. Different from ST-18 and ST-22, only one auto-ignition point takes place at 3.2 CAD. The flame induced by auto-ignition propagates at a fast speed due to the high thermodynamics near the TDC, consequently, it sweeps the position where the second auto-ignition is supposed to occur even before the second auto-ignition occurs, leading to the absence of second auto-ignition. On the contrary, the flame in the left side of auto-ignition propagates at a slow speed. As a result, there are still mixtures remains unconsumed at 3.9 CAD. Meanwhile, a small auto-ignition occurs near the exhaust valve. Limited by the insufficient unburned mixture, the pressure rise induced by this auto-ignition is negligible, thus which is not discussed in detail in present work.

3.2 CAD

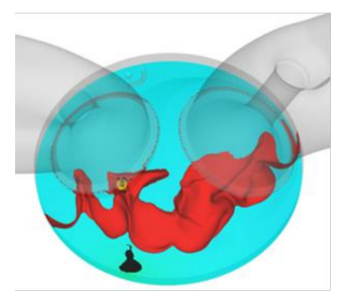

3.7 CAD

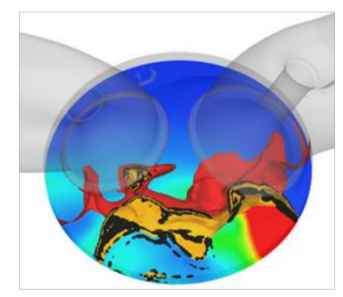

3.4 CAD

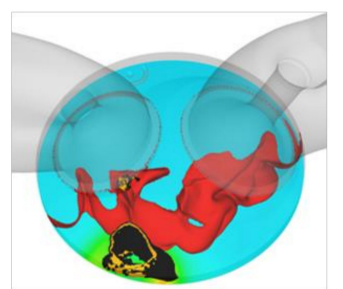

3.8 CAD

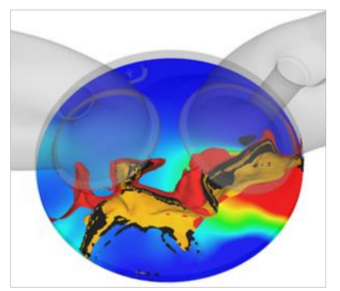

3.6 CAD

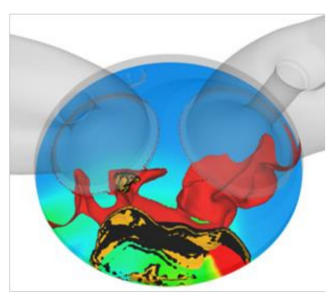

3.9 CAD
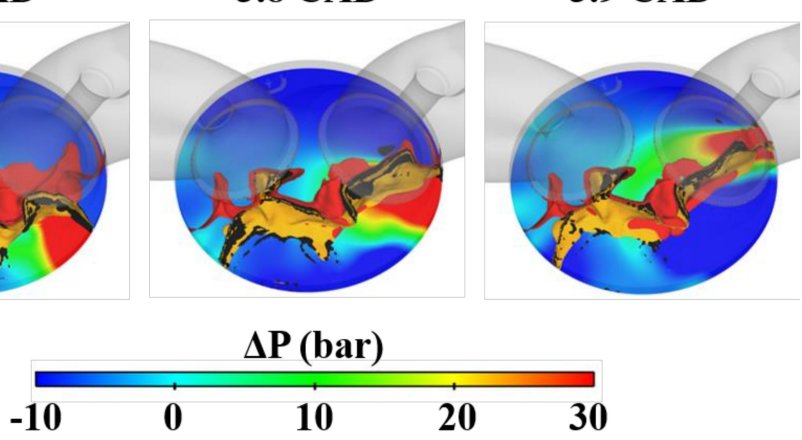

30

Figure 14. Evolution of $3 \mathrm{D}$ isosurface of $\mathrm{G}=0$ and $\mathrm{T}=1600 \mathrm{~K}$ in-cylinder combustion process at $\mathrm{ST}=-26 \mathrm{CAD}$.

An obvious pressure wave in flame front can be seen from the distribution of pressure fluctuation during 3.6 to 3.8 CAD bTDC in Figure 15. In addition, the position of pressure wave is well consistent with the flame front induced by auto-ignition that is marked by $\mathrm{Y}_{\mathrm{HCO}}=3 \mathrm{ppm}$, indicating the pressure wave and auto-ignition flame front are coupled and propagate with same velocity forwards to unburned mixture region. As a result, the coupling increases the local pressure dramatically and lowers the ignition delay time of local unburnt mixture, which attributes to the quick auto-ignition occurrence and release a lot of heat, and in turn maintains the propagation of pressure wave. A positive feedback is thus formed. The propagation velocity of auto-ignition flame from $3.6 \mathrm{CAD}$ to $3.8 \mathrm{CAD}$ is $1.7 \mathrm{Km} / \mathrm{s}$, which is much larger than the value of local acoustic speed $650 \mathrm{~m} / \mathrm{s}$. The max pressure in the flame front is $30 \mathrm{MPa}$. The C-J detonation velocity is [32]:

$$
D_{C J}=\sqrt{2\left(\gamma^{2}-1\right) Q}
$$

and the C-J pressure of burned mixture is:

$$
P_{C J} \cong \rho_{0} \frac{D_{C J}^{2}}{\gamma+1}
$$


where $Q, \gamma, \rho_{0}$ are the heat release amount of unit mass of mixture, the adiabatic exponent, the density of local unburned mixture. Specifically, $\gamma=1.4, \rho_{0}=20 \mathrm{~kg} / \mathrm{m}^{3}$, and the low heating value of gasoline is $44 \mathrm{MJ} / \mathrm{kg}$. Results calculated by Equation (7) and Equation (8) show that the detonation velocity is $2.3 \mathrm{~km} / \mathrm{s}$ and the detonation pressure is $44 \mathrm{MPa}$. It is noted that the Chapman-Jouguet theory is based on one-dimensional idealized mode, while the investigation in this work is conducted in 3D models. Though the propagation velocity of flame and the maximum pressure are lower than the CJ velocity and the CJ pressure, considering the difference between 1D and 3D, especially that they have same order of magnitude, it is reasonable to draw the conclusion that DDT occurs in present condition.

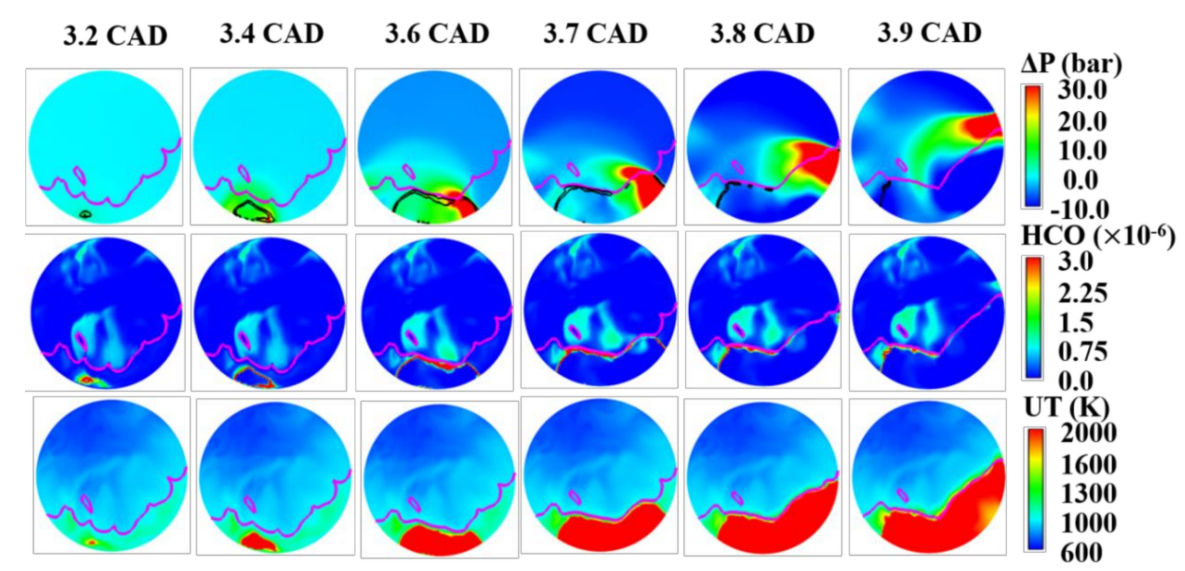

Figure 15. Evolutions of $\Delta \mathrm{P}$, mass fraction of $\mathrm{HCO}$ and unburned temperature after the initial auto-ignition at $\mathrm{ST}=-22 \mathrm{CAD}$.

To further validate the coupling between flame and pressure wave, a similar method is adopted to extract the pressure, temperature and mass fraction of HCO as shown in Figure 12. The detailed method can be found in Section 4.1. Figure 16 shows the evolution of $2 \mathrm{D}$ configuration of $\Delta \mathrm{P}$ in the horizontal cross-section (left), pressure, unburned temperature and mass fraction of HCO on the 1D profile (middle) and 2D configuration of unburned temperature in the horizontal cross-section (right) under the condition of ST-26. It can be seen from the 1D profile that pressure wave induced by the increase of local pressure appears at 3.2 CAD when the first auto-ignition occurs. However, the maximum pressure here is only $6.8 \mathrm{MPa}$, with a maximum pressure differential of $0.8 \mathrm{MPa}$. The dashed red line in the $2 \mathrm{D}$ configuration of $\Delta \mathrm{P}$ represents the initial pressure wave positions at different timings. During 3.2 CAD to $3.4 \mathrm{CAD}$, the right side of flame propagates outwardly with about $490 \mathrm{~m} / \mathrm{s}$, which is lower than that local sound speed. Thus, the autoignition induces a deflagration flame. As the pressure wave effects on the local thermodynamics, the ignition delay time of unburned mixture ahead of auto-ignition flame shortens.

Consequently, auto-ignition flame propagation velocity increases, which will generate new pressure wave. At 3.4 CAD bTDC, the maximum pressure value at right side of flame front achieves $8.5 \mathrm{MPa}$. The new pressure wave has a faster velocity than previous one due to local high thermodynamics. As the new pressure wave catches up the previous one, a strong pressure wave called shock wave forms. Thus, following the increase of flame propagation velocity, the transition of the autoignition modes is completed from the subsonic combustion to supersonic combustion. During 3.4 to $3.6 \mathrm{CAD}$ bTDC, the flame front velocity achieves $1.16 \mathrm{~km} / \mathrm{s}$. The distance between flame front and pressure wave gradually decreases and finally the coupling between flame front and pressure wave with a maximum pressure of $30 \mathrm{MPa}$ is observed. At this time, a detonation wave right in the flame front can be observed. As a consequence HCO decreased quickly and high temperature reaction became the predominant species in the combustion chamber, which is consistent with the optical experiment [24]. From 3.6 CAD to 3.8 CAD, the detonation propagates towards right at a speed of about $1.7 \mathrm{~km} / \mathrm{s}$, until the unburned mixture is exhausted. Thus, from $3.2 \mathrm{CAD}$ to $3.8 \mathrm{CAD}$, 
the flame propagation completes the combustion mode transition from sequential auto-ignition to detonation combustion.

In fact, the maximum spark advancing angle in practical engines is $-18 \mathrm{CAD}$, while in simulation, the value can be advanced to $-26 \mathrm{CAD}$ and $-28 \mathrm{CAD}$ in order to investigate super-knock, which, basically, is equivalent to the pre-ignition phenomenon in engines [17]. Therefore, the combustion process in this condition is equivalent to the super-knock caused by the end-gas detonation.
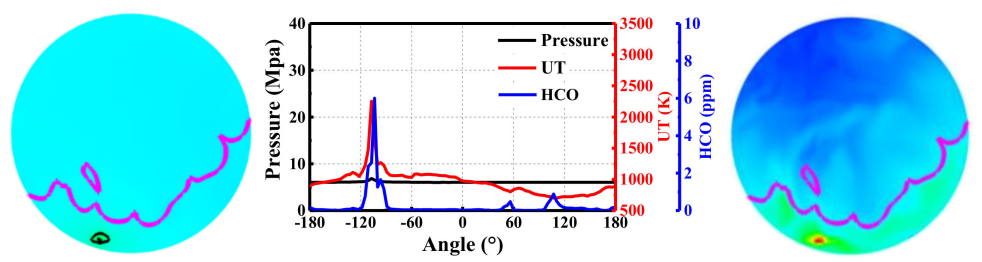

(a) 3.2 CAD
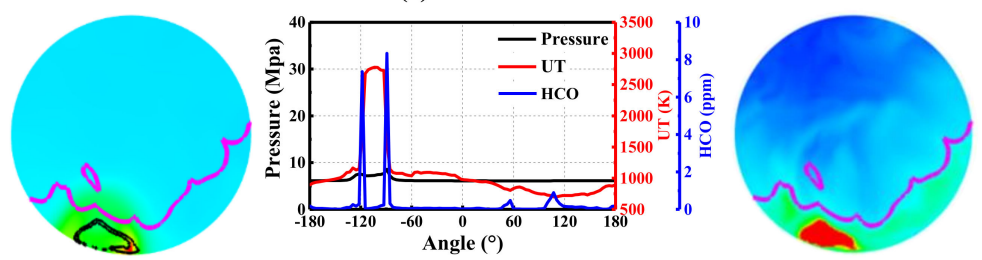

(b) 3.4 CAD
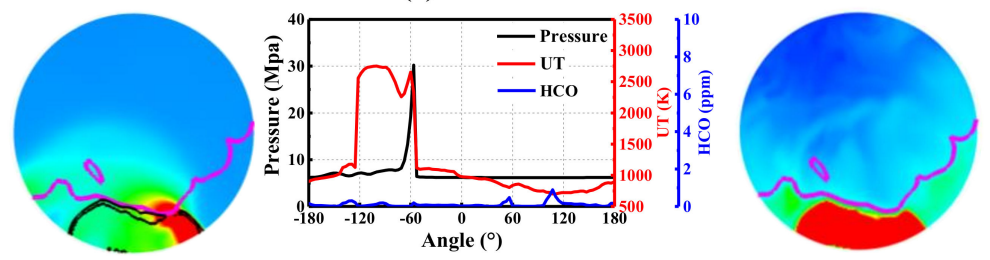

(c) 3.6 CAD
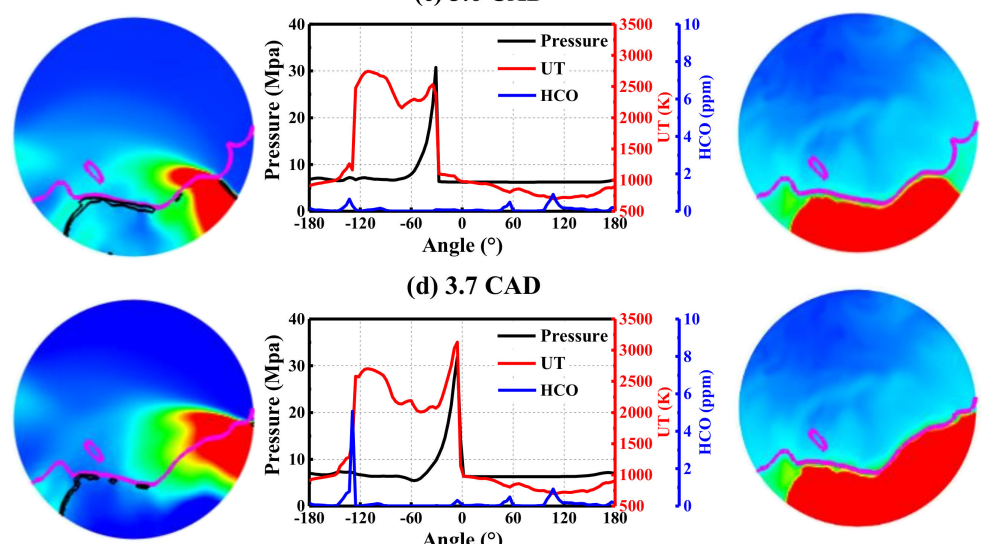

(d) 3.7 CAD
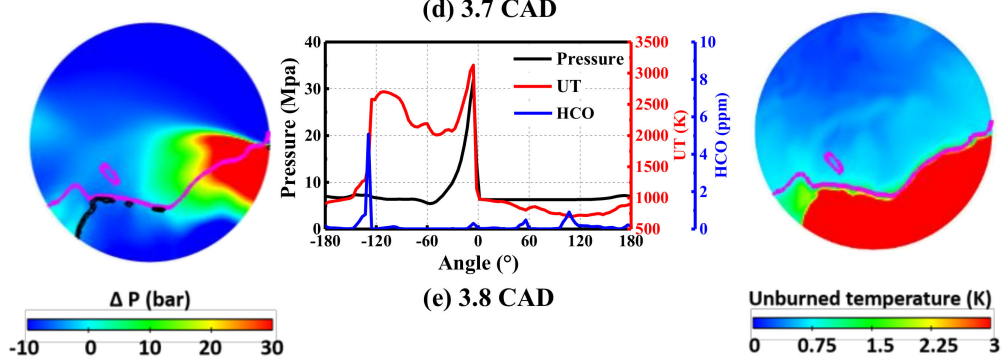

(e) 3.8 CAD
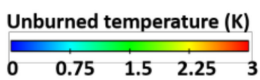

Figure 16. Evolutions of $2 \mathrm{D}$ configuration of $\Delta \mathrm{P}$ in the horizontal cross-section (left), pressure, unburned temperature and mass fraction of $\mathrm{HCO}$ on the 1D profile (middle) and 2D configuration of unburned temperature in the horizontal cross-section (right) under the condition of ST $=-26$ CAD. (a-e) corresponding to five different angles.

\section{Conclusions}

In present work, multidimensional LES simulations are employed to capture the different combustion modes in a downsized spark ignition gasoline engine. A G-equation turbulent combustion model is employed to track the turbulent flame front and SAGE coupled with detailed chemistry mechanism is used to capture end-gas autoignition near the wall. Here, the knock intensity and 
combustion mechanism under six spark timings are carefully investigated by experiment and LES. The results are concluded as follows:

(1) Along with the advance of spark timing, the pressure oscillation starts earlier with higher amplitude, and a transition from knock to super-knock appears. The super-knock is observed in ST-26 and ST-28, in which the peak pressure exceeds $30 \mathrm{MPa}$. Though the intensity of knock increases, the mass fraction of unburned mixture when AI occurs under different spark timings is similar. However, as the spark timing advances, the flame propagates faster. As a result, the combustion and onset of autoignition is more likely to occur at TDC, which brings end gas a higher temperature and pressure. It is reasonable to conclude that knock intensity is not only proportional to the mass fraction of mixtures burned by AI but the thermodynamics of it instead.

(2) In the conventional knock, the unburned mixture is preheated and compressed by the burned region as main flame propagates. Auto-ignition occurs at hot-spots near the cylinder wall, generating pressure waves. The thermodynamics state of remained unburned mixture is further increased under the coupling effects of the deflagration and the main flame until it is high enough to emerge new hot-spot that triggers second auto-ignition, generating stronger pressure waves as a result of higher HRR.

(3) For further advancing ST that corresponding to the pre-ignition in engines such as ST-26, ST-28, an intense knock called super-knock occurs. As the pressure wave effects induced by the autoignition in the end gas on the local thermodynamics, the ignition delay time of unburned mixture ahead of auto-ignition flame shortens. Consequently, auto-ignition flame propagation velocity increases, which will generate new strong pressure wave. Overall, following the increase of flame propagation velocity, the transition of the autoignition modes is achieved from the subsonic combustion to supersonic combustion. This allows the coupling between pressure wave and AI flame that reinforces each other, leading to the DDT and super-knock occurrences.

It should be noted that knock combustion also depends on the current combustion velocity and composition and temperature fluctuations in cylinder [41], which are responsible for the knock occurrence in different cycles. Thus, the knock mechanism in terms of cycle-to-cycle variations will be studied in our further work. This work only focuses on the mechanism of knock occurrence by advancing spark timing, thus the control of knock should be investigated in future work.

Author Contributions: Supervision, C.L.; Writing—original draft, L.Z.; Writing—review \& editing, C.L.

Funding: This research was funded by the National Natural Science Foundation of China (Grant No. 91641203, 51606133).

Conflicts of Interest: The authors declare no conflict of interest.

\section{Abbreviations}

$\begin{array}{llll}\text { AMR } & \text { Adaptive Mesh Refinement } & \text { AI } & \text { Auto-ignition } \\ \text { aTDC } & \text { after Top Dead Center } & \text { BMF } & \text { Burned Mass Fraction } \\ \text { bTDC } & \text { before Top Dead Center } & \text { CFD } & \text { Computational Fluid Dynamics } \\ \text { CJ } & \text { Chapman-Jouguet } & \text { DDT } & \text { Deflagration to Detonation Transition } \\ \text { DNS } & \text { Direct Numerical Simulation } & \text { ECFM-LES } & \text { Extended Coherent Flame Model for LES } \\ \text { GDI } & \text { Gasoline Direct Injection } & \text { HCCI } & \text { Homogeneous charge compression ignition } \\ \text { HRR } & \text { Heat Release Rate } & \text { LES } & \text { Large Eddy Simulation } \\ \text { MAPO } & \text { maximum amplitude of pressure } & \text { RANS } & \text { Reynolds averaged Navier-Stokes } \\ & \text { oscillations } & & \\ \text { PRF } & \text { Primary Reference Fuel } & \text { PID } & \text { Proportional-Integral-Derivative } \\ \text { ST } & \text { Spark Timing } & \text { SI } & \text { Spark Ignition } \\ \text { TKI } & \text { Tabulated Kinetics for Ignition } & \text { TDC } & \text { Top Dead Center }\end{array}$




\section{References}

1. Rudloff, J.; Zaccardi, J.M.; Richard, S.; Anderlohr, J.M. Analysis of pre-ignition in highly charged SI engines: Emphasis on the auto-ignition mode. Proc. Combust. Inst. 2013, 34, 2959-2967. [CrossRef]

2. Sharma, N.; Patel, C.; Tiwari, N.; Agarwal, A.K. Experimental investigations of noise and vibration characteristics of gasoline-methanol blend fuelled gasoline direct injection engine and their relationship with combustion characteristics. Appl. Ther. Eng. 2019, 158, 113754. [CrossRef]

3. Wei, H.; Yu, J.; Zhou, L. Improvement of engine performance with high compression ratio based on knock suppression using Miller cycle with boost pressure and split injection. Front. Energy 2019. [CrossRef]

4. Wei, H.; Gao, D.; Zhou, L.; Feng, D.; Chen, R. Different combustion modes caused by flame-shock interactions in a confined chamber with a perforated plate. Combust. Flame 2017, 178, 277-285. [CrossRef]

5. Wang, Z.; Liu, H.; Song, T.; Qi, Y.; He, X.; Shuai, S.; Wang, J. Relationship between super-knock and pre-ignition. Int. J. Engine Res. 2015, 16, 166-180. [CrossRef]

6. Wang, Z.; Liu, H.; Reitz, R.D. Knocking combustion in spark-ignition engines. Prog. Energy Combust. Sci. 2017, 61, 78-112. [CrossRef]

7. $\mathrm{Xu}, \mathrm{H}$.; Gao, J.; Yao, A.; Yao, C. The effect of the energy convergence and energy dissipation on the formation of severe knock. Appl. Energy 2018, 228, 1243-1254. [CrossRef]

8. Vafamehr, H.; Cairns, A.; Sampson, O.; Koupaie, M.M. The competing chemical and physical effects of transient fuel enrichment on heavy knock in an optical spark ignition engine. Appl. Energy 2016, 179, 687-697. [CrossRef]

9. Zaccardi, J.-M.; Escudié, D. Overview of the main mechanisms triggering low-speed pre-ignition in spark-ignition engines. Int. J. Engine Res. 2015, 16, 152-165. [CrossRef]

10. Wei, H.; Zhao, J.; Zhou, L.; Xu, Z.; Gao, D. Pressure oscillation with destructive effect of flame propagation of a stoichiometric hydrogen-air mixture in a confined space. J. Hazard. Mater. 2018, 344, 1025-1033. [CrossRef]

11. Konig, G.; Sheppard, C.G.W. End Gas Autoignition and Knock in a Spark Ignition Engine; SAE Transactions; SAE International: Tulsa, OK, USA, 1990; pp. 820-839.

12. Bates, L.; Bradley, D. Deflagrative, auto-ignitive, and detonative propagation regimes in engines. Combust. Flame 2017, 175, 118-122. [CrossRef]

13. Amann, M.; Mehta, D.; Alger, T. Engine Operating Condition and Gasoline Fuel Composition Effects on Low-Speed Pre-Ignition in High-Performance Spark Ignited Gasoline Engines. SAE Int. J. Engines 2011, 4, 274-285. [CrossRef]

14. Steurs, K.; Blomberg, C.; Boulouchos, K. Formulation of a Knock Model for Ethanol and Iso-Octane under Specific Consideration of the Thermal Boundary Layer within the End-Gas. SAE Int. J. Engines 2014, 7, 1752-1772. [CrossRef]

15. Wei, H.; Feng, D.; Pan, J.; Shao, A.; Pan, M. Knock characteristics of SI engine fueled with n-butanol in combination with different EGR rate. Energy 2017, 118, 190-196. [CrossRef]

16. Wei, H.; Feng, D.; Pan, M.; Pan, J.; Rao, X.; Gao, D. Experimental investigation on the knocking combustion characteristics of n-butanol gasoline blends in a DISI engine. Appl. Energy 2016, 175, 346-355. [CrossRef]

17. Zhou, L.; Kang, R.; Wei, H.; Feng, D.; Hua, J.; Pan, J.; Chen, R. Experimental analysis of super-knock occurrence based on a spark ignition engine with high compression ratio. Energy 2018, 165, 68-75. [CrossRef]

18. Bares, P.; Selmanaj, D.; Guardiola, C.; Onder, C. A new knock event definition for knock detection and control optimization. Appl. Ther. Eng. 2018, 131, 80-88. [CrossRef]

19. Shen, X.; Zhang, Y.; Shen, T. Cylinder pressure resonant frequency cyclic estimation-based knock intensity metric in combustion engines. Appl. Ther. Eng. 2019, 158, 113756. [CrossRef]

20. Zhou, L.; Shao, A.; Hua, J.; Wei, H.; Feng, D. Effect of Retarded Injection Timing on Knock Resistance and Cycle to Cycle Variation in Gasoline Direct Injection Engine. J. Energy Resour. Technol. 2018, 140, 072202. [CrossRef]

21. Zhou, L.; Gao, D.; Zhao, J.; Wei, H.; Zhang, X.; Xu, Z.; Chen, R. Turbulent flame propagation with pressure oscillation in the end gas region of confined combustion chamber equipped with different perforated plates. Combust. Flame 2018, 191, 453-467. [CrossRef]

22. Wei, H.; Zhang, X.; Zeng, H.; Deiterding, R.; Pan, J.; Zhou, L. Mechanism of end-gas autoignition induced by flame-pressure interactions in confined space. Phys Fluids 2019, 31, 076106. 
23. Wei, H.; Zhao, J.; Zhang, X.; Pan, J.; Hua, J.; Zhou, L. Turbulent flame-shock interaction inducing end-gas autoignition in a confined space. Combust. Flame 2019, 204, 137-141. [CrossRef]

24. Merola, S.S.; Vaglieco, B.M. Knock investigation by flame and radical species detection in spark ignition engine for different fuels. Energy Convers. Manag. 2007, 48, 2897-2910. [CrossRef]

25. Kawahara, N.; Tomita, E.; Sakata, Y. Auto-ignited kernels during knocking combustion in a spark-ignition engine. Proc. Combust. Inst. 2007, 31, 2999-3006. [CrossRef]

26. Tanoue, K.; Jimoto, T.; Kimura, T.; Yamamoto, M.; Hashimoto, J. Effect of initial temperature and fuel properties on knock characteristics in a rapid compression and expansion machine. Proc. Combust. Inst. 2017, 36, 3523-3531. [CrossRef]

27. Westbrook, C.K.; Mehl, M.; Pitz, W.J.; Sjöberg, M. Chemical kinetics of octane sensitivity in a spark-ignition engine. Combust. Flame 2017, 175, 2-15. [CrossRef]

28. Yang, Y.; Dec, J.E.; Sjöberg, M.; Ji, C. Understanding fuel anti-knock performances in modern SI engines using fundamental HCCI experiments. Combust. Flame 2015, 162, 4008-4015. [CrossRef]

29. Wang, Z.; Qi, Y.; He, X.; Wang, J.; Shuai, S.; Law, C.K. Analysis of pre-ignition to super-knock: Hotspot-induced deflagration to detonation. Fuel 2015, 144, 222-227. [CrossRef]

30. Wang, Z.; Qi, Y.; Liu, H.; Zhang, P.; He, X.; Wang, J. Shock wave reflection induced detonation (SWRID) under high pressure and temperature condition in closed cylinder. Shock Waves 2016, 26, 687-691. [CrossRef]

31. D'Adamo, A.; Breda, S.; Fontanesi, S.; Irimescu, A.; Merola, S.S.; Tornatore, C. A RANS knock model to predict the statistical occurrence of engine knock. Appl. Energy 2017, 191, 251-263. [CrossRef]

32. Robert, A.; Richard, S.; Colin, O.; Poinsot, T. LES study of deflagration to detonation mechanisms in a downsized spark ignition engine. Combust. Flame 2015, 162, 2788-2807. [CrossRef]

33. Yu, H.; Chen, Z. End-gas autoignition and detonation development in a closed chamber. Combust. Flame 2015, 162, 4102-4111. [CrossRef]

34. Wang, Z.; Wang, Y.; Reitz, R.D. Pressure Oscillation and Chemical Kinetics Coupling during Knock Processes in Gasoline Engine Combustion. Energy Fuel 2012, 26, 7107-7119. [CrossRef]

35. Zhou, L.; Dong, K.; Hua, J.; Wei, H.; Chen, R.; Han, Y. Effects of applying EGR with split injection strategy on combustion performance and knock resistance in a spark assisted compression ignition (SACI) engine. Appl. Ther. Eng. 2018, 145, 98-109. [CrossRef]

36. Livengood, J.C.; Wu, P.C. Correlation of autoignition phenomena in internal combustion engines and rapid compression machines. Symp. Int. Combust. 1955, 5, 347-356. [CrossRef]

37. Heywood, J.B. Internal Combustion Engine Fundamentals; McGraw-Hill Education: New York, NY, USA, 1988.

38. Lafossas, F.-A.; Castagne, M.; Dumas, J.-P.; Henriot, S. Development and Validation of a Knock Model in Spark Ignition Engines Using a CFD Code; Report No. 0148-7191; SAE Technical Paper; SAE International: San Diego, CA, USA, 2002.

39. Shao, J.; Rutland, C. Modeling Investigation of Auto-Ignition and Engine Knock by HO2; Report No. 0148-7191; SAE Technical Paper; SAE International: Detroit, MI, USA, 2014.

40. Réveillé, B.; Duparchy, A. 3D CFD analysis of an abnormally rapid Combustion phenomenon in downsized gasoline engines. Oil Gas Sci. Technol. Rev. de l'IFP 2009, 64, 431-444.

41. Robert, A.; Richard, S.; Colin, O.; Martinez, L.; de Francqueville, L. LES prediction and analysis of knocking combustion in a spark ignition engine. Proc. Combust. Inst. 2015, 35, 2941-2948. [CrossRef]

42. Pal, P.; Wu, Y.; Lu, T.; Som, S.; See, Y.C.; le Moine, A. Multidimensional Numerical Simulations of Knocking Combustion in a Cooperative Fuel Research Engine. J. Energy Resour. Technol. 2018, 140, 102205. [CrossRef]

43. Lecocq, G.; Richard, S.; Michel, J.-B.; Vervisch, L. A new LES model coupling flame surface density and tabulated kinetics approaches to investigate knock and pre-ignition in piston engines. Proc. Combust. Inst. 2011, 33, 3105-3114. [CrossRef]

44. Zhou, L.; Hua, J.; Wei, H.; Dong, K.; Feng, D.; Shu, G. Knock characteristics and combustion regime diagrams of multiple combustion modes based on experimental investigations. Appl. Energy 2018, 229, 31-41. [CrossRef]

45. Tan, Z.; Reitz, R.D. Development of a Universal Turbulent Combustion Model for Premixed and Direct Injection Spark/Compression Ignition Engines; SAE International: Detroit, MI, USA, 2004.

46. Liang, L.; Reitz, R.D.; Iyer, C.O.; Yi, J. Modeling Knock in Spark-Ignition Engines Using a G-equation Combustion Model Incorporating Detailed Chemical Kinetics; SAE International: Detroit, MI, USA, 2007. 
47. Liu, Y.-D.; Jia, M.; Xie, M.-Z.; Pang, B. Enhancement on a Skeletal Kinetic Model for Primary Reference Fuel Oxidation by Using a Semidecoupling Methodology. Energy Fuels 2012, 26, 7069-7083. [CrossRef]

48. Senecal, P.K.; Pomraning, E.; Richards, K.J.; Briggs, T.E.; Choi, C.Y.; McDavid, R.M.; Patterson, M.A. Multi-Dimensional Modeling of Direct-Injection Diesel Spray Liquid Length and Flame Lift-off Length Using CFD and Parallel Detailed Chemistry; SAE International: Detroit, MI, USA, 2003.

49. Ewald, J.; Peters, N. A Level Set Based Flamelet Model for the Prediction of Combustion in Spark igNition Engines. In Proceedings of the 15th International Multidimensional Engineering Models User Group, Detroit, MI, USA, 11 April 2005; pp. 1-6.

50. Metghalchi, M.; Keck, J.C. Burning velocities of mixtures of air with methanol, isooctane, and indolene at high pressure and temperature. Combust. Flame 1982, 48, 191-210. [CrossRef]

51. Gülder, Ö.L. Correlations of Laminar Combustion Data for Alternative SI Engine Fuels; Report No. 0148-7191; SAE Technical Paper; SAE Internaional: San Diego, CA, USA, 1984.

52. Yoshizawa, A.; Horiuti, K. A statistically-derived subgrid-scale kinetic energy model for the large-eddy simulation of turbulent flows. J. Phys. Soc. Jpn. 1985, 54, 2834-2839. [CrossRef]

53. Menon, S.; Calhoon, W.H. Subgrid mixing and molecular transport modeling in a reacting shear layer. Symp. Int. Combust. 1996, 26, 59-66. [CrossRef]

54. Reitz, R. Modeling atomization processes in high-pressure vaporizing sprays. At. Spray Technol. 1987, 3, 309-337.

55. Amsden, A.A.; Findley, M. KIVA-3V: A Block-Structured KIVA Program for Engines with Vertical or Canted Valves; Lawrence Livermore National Lab(LLNL): Livermore, CA, USA, 1997.

(C) 2019 by the authors. Licensee MDPI, Basel, Switzerland. This article is an open access article distributed under the terms and conditions of the Creative Commons Attribution (CC BY) license (http://creativecommons.org/licenses/by/4.0/). 